\title{
A TELEVISÃO \\ E AS CRIANÇAS ${ }^{1}$
}

\section{O tema televisão e criança tem sido bastante estudado por}

pesquisadores de todo o mundo. As linhas de pesquisa se multiplicam e as abordagens científicas do tema têm trazido contribuições significativas para os estudiosos de diversas áreas do conhecimento. Neste número de Comunicação \& Educação publicamos, com exclusividade em língua portuguesa, artigo da revista Tendência da Pesquisa em Comunicação, do Centro para o Estudo da Comunicação e Cultura, da Universidade de St. Louis, que faz um levantamento sobre as abordagens teóricas e os resultados de diversas pesquisas realizadas sobre a temática da audiência de televisão pelas crianças.

\section{UM BALANÇO}

\section{DAS RECENTES PESQUISAS ${ }^{2}$}

A tecnologia possibilita ampliar significativamente as maneiras de se utilizar o aparelho de televisão. Estudos recentes documentam o uso extensivo que as crianças fazem dos videocassetes, computadores e televisão a cabo. Porém, um exame detalhado dos mais recentes relatos de pesquisa poderá constatar muitas questões que não têm sido pesquisadas, ou seja, que há tão poucas evidências, nas pesquisas já realizadas, sobre as novas possibilidades de uso da televisão. Até agora a relação câmera de vídeo/trabalho criativo na tela, analogamente à relação escrita/leitura, está notoriamente ausente das pesquisas, apesar do uso indevido do termo "literatura televisiva". Também faz falta uma descrição mais precisa sobre o modelo padrão de conteúdo da experiência visual das crianças, em termos de programas e gêneros, e quais as conseqüências culturais dele derivadas. Um tema recorrente nessas novas pesquisas é, entretanto, o reconhecimento da criança como um espectador ativo, que seleciona e interpreta o que vê em termos de um desenvolvimento de estruturas mentais ou schema. Uma equipe da Michigan State University ${ }^{3}$ relata que "a televisão a cabo numa casa pode resultar num acesso aos
OS AUTORES
W. Cordelian
Juan Antonio Gaitan
Guillermo Orozco Gomez

$\overline{1 .}$ O texto que ora traduzimos compõe o número 4 do volume 13, de 1993, da revista Tendência da Pesquisa em Comunicação, do Centro para o Estudo da Comunicação e Cultura, da Universidade de St. Louis, EUA, cujo editor é William E. Biernatzki, S.J.

2. W. Cordelian é o autor desta primeira parte do artigo.

3. ATKIN, D.J.; GREENBERG, B.S.; BALDWIN, T. The home ecology of children's television viewing: parental mediation and the new video environment. (A ecologia doméstica da assistência infantil à televisão: a mediação dos pais e o novo ambiente eletrônico). Joumal of Communication, Michigan States University 41(3), 1991. p.40-51. 
programas adequados na mesma medida que aos inadequados". A pesquisa ouviu mais de 800 crianças e adolescentes da quinta série de primeiro grau à segunda série do segundo grau (sem focar exatamente faixas etárias alunos da segunda série do segundo grau são adolescentes) e revelou que a maioria dos pesquisados assiste a filmes $\mathrm{R}$ (restritos, ou seja, considerados inadequados para determinada faixa etária), sem que a assistência a esses programas estivesse relacionada a restrições paternas. Entretanto, aqueles que mais assistiam a filmes $R$ (restritos) também tendiam a declarar sofrer maior restrição por parte dos pais (sem se levar em consideração idade e outros atributos).

As atividades paralelas das equipes de Greenberg desenvolveram-se em âmbito internacional, para documentar padrões de uso da televisão e interação familiar entre populações escolares. Isso foi feito no Japão, China, Coréia, Taiwan, e na Inglaterra, Holanda, Bélgica, Suécia, Espanha, Alemanha, além dos Estados Unidos. Cópias desses estudos encontram-se disponíveis nos escritórios do Professor Greenberg 4 .

Com relação às tecnologias disponíveis para as crianças, Wartella ${ }^{5}$ pesquisou a próspera comunidade branca de Champaign-Urbana, onde uma em cada cinco crianças não tem acesso à TV a cabo, utilizando portanto o videocassete e as redes de emissão existentes. Nessas redes, a programação infantil constava exclusivamente de desenhos animados. A programação da emissora de TV pública consistia de $70 \%$ de informação; entretanto essa programação era menos assistida. O estudo é esclarecedor ao focar aspectos positivos do que está disponível e é usado; mas, ao assim fazer, não revela as "sombras" de uma experiência empobrecida que atinge significativo contingente das minorias naquela comunidade. Para outros mercados mais urbanizados, os dados de 1992 sugerem que ainda há muito por fazer no que diz respeito a melhorar a experiência de toda a população infantil.

Como mensurar o quanto as crianças têm assistido à TV? Van der Voort ${ }^{6}$ comparou o que ele chamou de "estimativas diretas" (a criança relata quantas horas por dia assiste à TV) com os registros diários de tempo de uso, dividido em blocos de quinze minutos. As correlações eram bastante boas (mais ou menos 0.5 ) porém menos efetivas entre crianças mais novas e naquelas de status sócio-econômico mais baixo. Van der Voorst parte do princípio de que os registros diários são mais corretos.

Quanto aos processos de percepção e interpretação, Flavell ${ }^{7}$ demonstra que as crianças de três e quatro anos de idade são capazes de interpretar as imagens na tela como representações de objetos reais; as de três anos são, porém, menos capazes de fazer ou revelar tal distinção perceptiva.

Sheppard ${ }^{8}$ testou crianças de seis a nove anos, encontrando diferentes elementos de com-

4. Professor B.S. Greenberg, Dept. of Telecommunications, Michigan State University, E. Lansing, MI 48224-1212.b.

5. V.WARTELLA, E; et al. Television and beyond. Children's video media in the community. (Televisão e muito mais. Os meios videográficos infantis na comunidade). Communication Research, n. 1, 1991. p.45-64.

6. VAN DER VOORT, T.H.A.; VOOIJIS, M. Validity of children's direct estimates of time spent television viewing. (A validade do tempo estimado que as crianças dedicam à assistência à televisão). Journal of Broadcasting and Electronic Media, 34(1), 1990. p.93-99.

7. FLAVELL, H.H.; et al. Do young children think of television images as pictures or real objects? (Crianças pequenas entendem as imagens da televisão como representações ou objetos reais?). Journal of Broadcasting and Electronic Media, 34(4), 1990. p.399-419.

8. SHEPPARD, A. Children, television and morality. Study II. (A criança, a televisão e a moralidade. Estudo II.). Broadcasting Standards Council. Relatório de Pesquisa, 1992. 
preensão em três programas que exibiu: as crianças mais novas demonstraram pouca compreensão dos motivos e caráter das personagens, e relataram um fraco entendimento da ação, apesar de terem sempre uma interpretação própria sobre aquilo a que assistiram. Mesmo as de nove anos, nem sempre interpretavam corretamente a "dimensão moral específica" (isto é, quem age incorretamente e é punido, e por quê) nas duas peças exibidas que não eram desenho animado. Wilson ${ }^{9}$ exibiu uma peça na qual era mostrado um sonho, e examinou se as crianças de seis a 12 anos eram capazes de entender que o que viam era a representação de um sonho. Se mostrado o contexto de uma criança na cama (o sonhador), com a imagem do sonho entrando por fusão ou através do uso de outros efeitos especiais, todas elas conseguiam entender que era sonho. Também ficou claro que a exibição daquele contexto reduzia qualquer percepção negativa do seu conteúdo.

Cantor e Hoffner ${ }^{10}$ trabalharam na direção oposta e descobriram, entre crianças de cinco a oito anos, altos níveis de medo, verbalizados especificamente ou perceptíveis através das expressões faciais observadas quando as crianças entendiam que as ameaças ali mostradas existiam na sua realidade local.
Dorr ${ }^{11}$ e seus colegas detectaram de que maneira as crianças comparavam as vidas familiares reais que elas conheciam com a representação de duas famílias ficcionais a que assistiam com maior frequiência. Esses julgamentos do "realismo social" dependiam tanto da idade e experiência dos espectadores quanto do contexto do que era exibido. Um estudo semelhante feito com mais de 600 crianças inquiria sobre o conhecido Cosby Show. Austin ${ }^{12}$ e sua equipe descobriram que a discussão dos programas em família ajuda a formar uma mais segura compreensão da realidade, e quanto mais as crianças considerassem a Família Huxtable como diferente da sua própria família, menos realista era considerada a família ficcional. Gunter ${ }^{13}$ e sua equipe basearam suas observações em discussões de grupo que envolviam crianças de sete a 15 anos, e ilustraram com abundantes excertos de diálogos como as crianças interpretavam ao que assistiam.

Embora esses estudos cobrissem diferentes gêneros, não se desenvolveu grande coisa sobre a percepção infantil dos seriados de ação e aventura, ou sobre os filmes de suspense, nos quais se pode localizar a ficção potencialmente mais perturbadora. Liddell $\mathrm{e}$ Masilela ${ }^{14}$ detectaram que quatro em cada dez crianças sul-africanas com idades de três a seis anos assistiam a programas pré-escola-

9. WILSON, B.J. Children's reactions to dreams conveyed in mass media programming. (As reações das crianças aos sonhos exibidos na programação de meios de comunicação de massa). Communication Research, 18 n.3, 1990. p.283-305.

10. CANTOR, J.; HOFFNER, C. Children's fear reactions to a televised film as a function of perceived immediacy of depicted threat. (As reações de medo das crianças ao filme televisivo como função da compreensão da proximidade do perigo descrito). Journal of Broadcasting and Electronic Media, 34, n.4, 1990. p.421-442.

11. DORR, A.; KORARIC, P; DONBLEDLY, C. Age and content influences on children's perceptions of the realism of television families. (As influências da idade e conteúdo sobre a percepção infantil do realismo das famílias televisivas). Journal of Broadcasting and Electronic Media, 34(4), 1990. p.377-397.

12. AUSTIN, E.W.; ROBERTS, D.F.; NASS, C.I. Influences of family communication on children's television-interpretation process. (As influências da comunicação familiar no processo infantil de interpretação da televisão). Communication Research 17 n. 4, 1990. p.545-564.

13. GUNTER, B.; MCALEER, J. Children and television. The one-eyed monster. (Criança e televisão. O monstro de um olho só). Londres: Routledge, 1990.

14. LIDDELL, C.; MASILELA, P. The use of pre-school education programs on radio and television by black south african children. ( $\mathrm{O}$ uso de programas educacionais pré-escolares por crianças negras sul africanas). Journal of Broadcasting and Electronic Media, 34(1), 1990. p.85-92. 
res em casa. Os autores defendiam a necessidade de se aumentar essa audiência e implementar maneiras de se integrar sua contribuição aos outros procedimentos educacionais. Durante a guerra de libertação do Kuwait, Wober e Young 15 descobriram que as crianças estavam a par dos acontecimentos da guerra seja através da televisão, seja por outros meios; elas não gostavam da guerra, não a viam como um "jogo de computador", responsabilizavam Saddam Hussein pessoalmente pela guerra e estavam tristes e zangadas com o sofrimento causado ${ }^{16}$.

Em 1991, foram publicados três livros, um francês (alegremente ilustrado), um americano e um inglês, que oferecem uma interpretação positiva dos benefícios da televisão assistida ativamente ${ }^{17}$.

\section{LIBERTAR A CRIANÇA DA TELEVISÃO E BANIR O MITO DA MÍDIA 18}

A falácia comportamental unidirecional de Lasswelli9 ainda aparece repetidamente nas pesquisas sobre o comportamento das crianças perante a televisão. Muitos ainda partem do pressuposto de que a iniciativa é exclusivamente do emissor e os efeitos, uma exclusividade da audiência. Par a par com essa crença está a suposição de que a televisão é poderosa e influenciadora e que uma audiência de crianças só pode ser passiva, desamparada e facilmente influenciada pela televisão. Essa abordagem inspirou por um lado, estudos centrados nos efeitos cognitivos e emocionais da mídia e, por outro, uma análise das possibilidades técnicas e educacionais que a televisão pode abrir para as crianças.

As pesquisas da década passada, entretanto, tenderam a relativizar a influência da televisão. Muitas variáveis demográficas, econômicas e sociológicas que afetam o contexto da recepção infantil estão sendo estudadas seriamente. A complexidade da situação está sendo melhor apreciada, e é clara a necessidade de maior colaboração interdisciplinar.

Entre os fatores componentes desta complexa equação estão os diversos agentes culturais (família, escola etc.) e a influência de fatores socializantes dos grupos primários (costumes, estilos e culturas grupais, posições sociais, níveis sócio-econômicos etc.) sobre o desenvolvimento cognitivo e social da criança.

$O$ aumento na quantidade e diversidade de equipamentos e canais audiovisuais, tanto em casa quanto na escola, traz novos fatores à experiência infantil. Torna-se evidente a necessidade de estudar essa experiência como um todo, e não apenas em aspectos limitados, mesmo que isso ainda seja difícil de se conseguir.

15. WOBER, J.M.; YOUNG, B.M.. The monster of the war. The children's knowledge of emotional reactions to and ways of making sense of the war against Iraq. ( $O$ monstro da guerra. $O$ conhecimento, reaçôes emocionais e a procura de sentido das crianças sobre a guerra contra o Iraque). In: GREENBERG, B.S.; GANTZ, W. (Eds.). Desert storm and the mass media (A tempestade no deserto e os meios de comunicação de massa), Hampton Press, 1992.

16. Outros estudos sobre a percepção infantil da guerra podem ser encontrados em Communication Research Trends, v.12, n. 3, 1992.

17. GUNTER, B.; MCALEER, J.; CLIFFORD, B. Children's views about television. (A visão infantil sobre a televisão). Avebury: Gower, 1991. HENRIOT, J.J. L'enfant, l'image et les media. (A criança, a imagem e os meios). Dammarie Les Lys: Edições SDT, 1991. SIGNOR1ELL1, N. A sourcebook on children and television (Um livro de referências sobre a criança e a televisão). Nova York: Greenwood Press, 1991.

18. Juan Antonio Gaitan é o autor do artigo que segue.

19. H. D. Lasswell, teórico da Comunicação, que na década de 30 formulou o conceito de "Comunicação de massa" (Teoria Hipodérmica), cujo fundamento se baseia na influência da mídia (principalmente da propaganda) sobre os receptores. Ver mais sobre o assunto em: WOLF, Mauro. Teorias de comunicação. 2.ed., Lisboa: Presença, 1992. (N.E.) 
Na Espanha, a pesquisa sobre TV e criança chegou a seu pico após a introdução massiva da mídia nos anos 60 e 70 . $O$ interesse de parte dessa pesquisa estava direcionado para a avaliação e melhoria da televisão institucional. Na década de 80 , a pesquisa diminuiu de volume e a atenção voltou-se para as novas tecnologias que estavam sendo introduzidas com grande velocidade. $O$ início dos canais de iniciativa privada nos anos 90 aumenta a necessidade de pesquisas, especialmente se a proposta for, nas regiões "autônomas", explorar comercialmente um determinado segmento da audiência, por exemplo a audiência infantil. Faz-se necessário muito mais pesquisa nessa área para basear firmemente as tomadas de decisão.

Numa tentativa de ir ao encontro dessa necessidade de se "pesquisar a pesquisa", Caffarel e Caceres ${ }^{20}$ publicaram recentemente um estudo bibliográfico sobre pesquisas básicas de comunicação na Espanha. Esse estudo demonstra que poucas são as pesquisas que estudam crianças, embora haja algum interesse na psicologia educacional da imagem e na semiologia da mídia audiovisual. Os estudos especificamente educacionais são mais abundantes; porém os estudos sobre o uso social são escassos, embora indispensáveis para a contextualização de uma pesquisa mais acurada ${ }^{21}$.

\section{Exposição e ambientes dos receptores da mídia}

Os telespectadores infantis da Espanha são em torno de 7 milhões. Sua preferência de horário de assistência é das cinco da tarde às nove da noite, de segunda à sexta-feira, e das duas da tarde até às cinco aos sábados, embora exista uma tendência crescente para a assistência em horários matutinos e noturnos, em parte como resultado do início da televisão privada e dos canais independentes de TV, mas sobretudo porque boa parte da audiência infantil também assiste à programação adulta.

De acordo com o Estudo Geral dos Meios (Estudio General de Medios), realizado no primeiro semestre de 1991 , as crianças entre quatro e 13 anos de idade assistem a uma média de três horas por dia de televisão. Pode-se especular que o maior tempo gasto na assistência à televisão foi tirado das horas anteriormente usadas para brincar com outras crianças. Isso pode levantar questões sobre o efeito que poderá ser causado no processo de socialização efetivo da criança. Um grande consumo de televisão numa idade mais tenra pode também contribuir para o declínio da assistência à TV por parte dos adolescentes, quando a atividade entre pares se torna mais atrativa.

Dentro do ambiente familiar, entretanto, a televisão ainda permanece como catalisador de interação entre os membros da família. A tendência familiar para assistir mais à TV obrigará a criança a também fazê-lo, participando assim dessa atividade comum da família. As interações familiares, de qualquer natureza, também tendem a acontecer sempre com uma televisão ligada como pano de fundo. Muitos outros fatores entram na experiência infantil em relação à TV em casa, tais como os horários de trabalho dos pais, o número de aparelhos de TV disponíveis na casa, a atitude dos pais etc.

Em resumo, os estudiosos da mídia tendem a demover a televisão e outras mídias de

20. CAFFAREL, C.; et al. Análisis cualitativo de la bibliografía sobre la investigación en comunicación en España. (Análise qualitativa da bibliografia de pesquisa sobre comunicação na Espanha). Madri, Associación de Investigadores en Comunicación del Estado Español (AICE), 1991.

21. MARTIN SERRANO, M. El uso de la comunicación social en España. (O uso da comunicação social na Espanha). Madri: CIS, 1982. 
um papel onipotente e considerá-la parte de um ambiente mais complexo, repleto de interações. Podem ser uma parte importante, mas em alguns casos seus efeitos diretos podem ser praticamente neglicenciados.

As interações familiares, e não a mídia de massa, permanecem sendo os fatores de maior importância no desenvolvimento infantil.

\section{Conteúdo da TV}

\section{e as Atitudes do Espectador}

Roche $^{22}$ estudou os modelos de desempenho "pró-social" e "agressivo" apresentados pela TV Catalunha na década de 80, perseguindo o interesse de psicólogos educacionais na otimização do papel social da programação de televisão em geral. $\mathrm{O}$ modelo resultante oferece linhas de atuação para a intervenção educacional aplicada à experiência real, ao longo de toda a carreira educacional, da pré-escola à universidade.

As "regras" para a formação de atitudes críticas nas escolas podem ser adaptadas para uso na família.

Roche sugere um plano para "descondicionamento pró-social televisivo" a ser seguido pelos pais antes, durante e depois de períodos de assistência à televisão, e os pais são vistos como "metacomunicadores", que devem expressar claramente sua aprovação ou desaprovação sobre conteúdos relevantes da programação enquanto assistem a ela com seus filhos.
Os critérios para os comentários são baseados em itens tais como: Como este programa trata a dignidade humana? Existe discriminação por razões de etnia, pobreza, profissão etc.?

A diretiva do Conselho da Comunidade Européia "Televisão sem Fronteiras", efetivada em 1992, obrigava os estados-membro a adotarem maneiras de evitar os efeitos perniciosos dos programas de televisão sobre o desenvolvimento físico, mental e moral dos menores. As televisões públicas na Espanha responderam de forma positiva, pelo menos até um certo ponto, porém os novos canais privados têm se limitado a produzir programação infantil com maior margem de rentabilidade, tais como programas de jogos. A maior parte do restante da programação infantil vem do Japão e dos Estados Unidos ${ }^{23}$.

Os estudiosos espanhóis acreditam que a publicidade responde acima de tudo a uma motivação econômica. J. Benavides ${ }^{24}$ diz que a publicidade usa a criança como ponto de venda, como um símbolo de uma das fases do ciclo de vida. A criança representa a abertura familiar, o estudante, o ser urbano, os valores lúdicos, um certo conservadorismo, segurança, vida, saúde, prazer etc., levando o espectador para um comportamento consumista exagerado, próprio de crianças descuidadas, porém fora de lugar num adulto responsável.

\section{A mídia no milênio que se aproxima}

Não mais precisamos pensar nas crianças como uma massa homogeneizada de "telecrianças", sem a influência de outra

22. ROCCHE, R. Violencia y prosocialidad, un programa para el descondicionamiento frente a la violencia en la imagen y para la educación de los comportamientos prosociales. (Violência e sociabilidade, um programa para o descondicionamento frente à violência na imagem e para a educação dos comportamentos sociais). In: LÓPEZ, A. (ed.) Que miras? Valencia, 1991, p.291-312.

23. CORTES, J.A. Interesa la audiencia infantil? (Interessa a audiência infantil?). In: LOPEZ, A. (ed.) Que miras? Valencia, 1991, p.185-204.

24. BENAVIDES, J. La imagen del niño en la publicidad. (A imagem da criança na publicidade). In: LOPEZ, A. (ed.) Que miras? Valencia, 1991, p.313-332. 
mídia que não seja a televisão. A situação atual da mídia é muito mais complexa do que tal análise pudesse supor. Dados sobre a televisão não descrevem a mídia de massa como um todo.

Livros, jornais, quadrinhos, tapes e discos, rádio, vídeos, computadores, video games etc., tudo ajuda a criar um cenário multimídia que tece sua vida diariamente, modelando a consciência das crianças, mas sempre agindo em conjunto com as relações interpessoais diretas.

Os equipamentos audiovisuais implantam-se nas escolas e nas famílias, e é crescente a pressão para um desenvolvimento ainda mais rápido de sua implantação. Na Espanha o Projeto Atenea pretendeu a introdução massiva de computadores nas escolas entre 1985 e 1989 . "Interativo" tornou-se palavra chave no que diz respeito à televisão e ao computador. J. Deval ${ }^{25}$ chamava a atenção para as possibilidades únicas de interação dos computadores e sua iminente integração com a televisão, o que geraria um grande potencial para instrução interativa. Alguns teóricos ${ }^{26}$ apontavam para uma relação educacional positiva nessas tecnologias, associadas a jogos de computador. A fácil interação eletrônica com outras pessoas a qualquer distância pode trazer uma nova dimensão à experiência infantil.

\section{TV E CRIANÇA DE UMA PERSPECTIVA LATINO-AMERICANA: O CASO DO MÉXICO27}

No México, como em outros países da América Latina - especialmente o Brasil e a Colômbia,$- o$ interesse na pesquisa das relações entre as crianças e a televisão tem aumentado rapidamente nos últimos anos. Estima-se que dois terços de toda a pesquisa sobre televisão realizada no México versa sobre os espectadores infantis. A maior parte desses estudos - cerca de $85 \%$ - foca os aspectos educativos dessa relação. Dedica-se especial atenção ao estudo dos efeitos da televisão sobre a identidade nacional das crianças enquanto mexicanas.

Embora, de acordo com Sanchez ${ }^{28}$ e Fuentes $^{29}, 70 \%$ dos projetos mexicanos de pesquisa sobre TV e crianças possam ser classificados como estudos sobre os Efeitos da Mídia, pode-se perceber um desenvolvimento teórico e metodológico no qual se podem distinguir pelo menos mais quatro modelos de pesquisas, a saber: "Necessidades, Usos e Gratificações da Audiência", "As Aplicações da Televisão", "Mediação Múltipla e Processo de Recepção", "Estratégias da Recepção da Televisão".

Próximo ao fím do milênio, a pesquisa mexicana sobre televisão e criança bem como a que é desenvolvida em outros países latino-americanos - se destaca como um campo fértil no qual diversos métodos quantitativos e qualitativos coexistem e são usados para reforço mútuo.

25. DEVAL, J. Niños y máquinas. Los ordenadores y la educación. (Crianças e máquinas. Os computadores e a educação). Madri: Alianza, 1986.

26. SOBRINO, M. A. Problemas teóricos y metodológicos que se plantean en la investigación de algunos de los nuevos productos informacionales de uso comunicativo. (Problemas teóricos e metodológicos que se colocam na pesquisa de alguns dos novos produtos informativos de uso comunicativo). Pesquisa distribuída no Terceiro Simpósio da Associación de Investigadores en Comunicación del Estado Español (AICE), 1992.

27. Guilherme Orozco Gomes é autor desta parte final do artigo.

28. SANCHEZ RUIZ, E. Teleadicción infantil: mito o realidad? (Teledependência infantil: mito ou realidade?) Guadalajara: Universidade de Guadalajara, 1989.

29. FUENTES, R. La investigación de la comunicación en Mexico, sistematización documental 1956-1986. (A pesquisa da comunicação no México, sistematização documental 1956-1986). Cidade do México: EDICOM, 1988. 


\section{$O$ impacto educativo da programação não-educativa}

Nos estudos mexicanos sobre os efeitos da mídia, duas correntes se desenvolve$\mathrm{ram}^{30}$. A primeira se concentra nos efeitos educacionais da programação não-educacional e foi esta a tendência que mais proliferou, dominando até cinco anos atrás ${ }^{31}$. O pressuposto básico era que a educação das crianças era influenciada mais fortemente pela programação regular das emissoras do que por programas especificamente educacionais. A segunda corrente dava maior atenção aos programas com intenções educacionais, tais como Vila Sésamo ${ }^{32}$ e programas de instrução como o Telesecundária, um programa de cursos da escola secundária produzidos especialmente para televisão ${ }^{33}$.

Um dos primeiros estudos realizados no México sobre a televisão e a criança foi feito por Cremoux ${ }^{34}$, que se preocupava com os efeitos nocivos da programação comercial. Seu estudo lidava com as variáveis de hábito de assistência: o tempo que as crianças passavam assistindo à televisão, o tipo de programação a que assistiam, seu estrato só- cio-econômico etc. $\mathrm{O}$ estudo concluía que a ideologia das emissoras comerciais era um fator mais preocupante do que o tempo que as crianças devotavam à televisão.

Desde este primeiro estudo, duas idéias passaram a dominar os estudos nessa área: a de que os jovens espectadores são mais vulneráveis aos efeitos da televisão do que os espectadores mais velhos, e que a programação comercial da televisão não é ideologicamente neutra, mas representa os interesses de empresas estrangeiras em detrimento dos valores nacionais.

Montoya e Rebei ${ }^{35}$ examinaram o papel da TV na socialização das crianças no período da educação básica, abordando explicitamente alguns dos mecanismos pelos quais a TV participa do processo cognitivo das crianças, como mediadora entre elas e a realidade. Este estudo e outros realizados mais tarde com a mesma ênfase ${ }^{36}$ mostravam a televisão e outras mídias de massa como criadoras de consenso e legitimadoras da autoridade pública. Esses estudos, bem como o de Medina ${ }^{37}$, apresentam dados que sustentam uma avaliação negativa do papel da televisão na educação infantil.

30. OROZCO GOMÉZ, G. La influencia de la TV en la educación de niños y jovenes: opiniones y mitos. (A influência da TV na educação infantil: opiniões e mitos). Um capítulo preparado para uma antologia sobre pesquisa da educação compilado por Pablo Latapi para publicação pela Editora Patria, Cidade do México, 1992.

31. OROZCO GOMÉZ, G. Televisión y producción de significados: tres ensayos. (Televisão e a produção de significados: três ensaios). Serie Comunicación y Sociedad, n.2, Guadalajara: Universidad de Guadalajara, 1987.

32. DIAZ GUERRERO et al. Learning by Televised Plaza Sesamo in Mexico. (Aprendendo através do programa Vila Sésamo no México) Journal of Educational Psychology (U.S.A), 1974.

33. CNTE Consejo Nacional Tecnico de la Educación. TV y ensenãnza en Mexico; el caso de la telesecundaria. (A TV e o ensino no México: O caso da telesecundária). Cidade do México: Gefe-SEP, 1993.

34. CREMOUX, R. La televisión y el alumno de telesecundária del Distrito Federal. (A televisão e o aluno de telesecundária do Distrito Federal). Cidade do México: Centro de Estudios Educativos, 1968.

35. MONTOYA, A.; REBElL, M.A. La televisión y los estudiantes de telesecundaria en Mexico. (A televisão e os estudantes de telesecundária no México). Cidade do México: Conselho Nacional Técnico de Educação (CNTE), 1983.

36. CHARLES, M. Nacionalismo, educación y medios de comunicación. (Nacionalismo, educação e meios de comunicação). Cidade do México: Universidad lberoamericana, 1987. (Dissertação de mestrado). MAYA, C. SILVA, M.I. El nacionalismo en los estudiantes de educación básica. (O nacionalismo nos estudantes de educação básica). Colección Documentos de Investigación Educativa, n.1, Mexico: UNP., 1989. REBEIL, M.A.; MONTOYA, A. (Eds.). Televisión y desnacionalización en Mexico. (Televisāo e desnacionalização no México) Colima: AMIC-Universidad de Colima, 1987. SANCHEZ RULZ, E. Televisión y representaciones políticas de escolares tapatios. (Televisão e representações políticas de escolares). Cuadernos de Comunicación y Sociedad, n.7, Guadalajara: CEIC - Universidad de Guadalajara, 1989.

37. MEDINA, J. Panorámica de la investigación sobre los efectos no didácticos de los medios de comunicación social en Mexico. (Uma visão panorâmica sobre os efeitos não didáticos dos meios de comunicação social no México). Cuadernos de Trabajo, n.1, México: AMIC, 1986. 
Por exemplo, eles sustentam que a criança sabe mais sobre o mundo tal como apresentado pela televisão do que sobre o mundo como descrito nas salas de aulas e nos livros didáticos. Também estão de acordo ao concluir que a TV ganha espaço nas mentes das crianças, e que a educação formal está perdendo o interesse para elas ${ }^{38}$.

\section{Necessidades, expectativas e a construção de identidades}

No México, entre os pesquisadores que estudam a criança e a televisão, a pesquisa dos "usos e gratificações" desenvolveu-se como uma antítese à pesquisa mais tradicional sobre "efeitos". Acosta ${ }^{39}$ foi o pioneiro dessa corrente, que atraiu outros jovens estudiosos nos anos 70, entre eles Fernandez e Batista; Bravo, Lambert e Perez, e Elkes ${ }^{40}$.

O pressuposto básico nesses estudos é o de que a audiência é ativa e não passiva. Rota $^{41}$ estimulou outros pesquisadores mexicanos a reconhecerem a TV como uma entre as muitas fontes de satisfação para as necessidades de informação e entretenimento, competindo com outros meios de comunicação de massa pela atenção do público.

Em outros estudos dessa natureza, Fernandez e equipe ${ }^{42}$ compararam o uso que as crianças fazem da TV com o uso que fazem de outros meios, enquanto Rota e Tremmel ${ }^{43}$ estudaram a relação da TV com a identificação cultural entre crianças do meio rural do sul do México. De acordo com eles, o controle dos pais se correlaciona de forma mais significativa com as preferências das crianças por programas estrangeiros, sendo a identidade cultural menos pronunciada entre as crianças das áreas urbanas do que entre as crianças da zona rural; o tipo de programação a que se assiste é mais relevante para a identidade infantil do que o tempo de assistência; e os estudantes mais velhos, que mostravam os melhores aproveitamentos nas escolas, eram os que possuíam os níveis mais altos de identidade nacional e cultural.

Dentro da mesma tradição, Makagamba ${ }^{44}$ estudou a televisão e as estruturas familiares entre famílias da fronteira com os Estados Unidos. Contrariamente às expectativas, a proximidade com a fronteira e a TV norte-americana tinham um efeito menor na

38. OROZCO GOMÉZ, G. Commercial TV and children's education in Mexico: the interaction of Socializing Institutions in the production of leaming. (A televisão comercial e a educação infantil no México: a interação das instituições sociais na produção do aprendizado). Cambridge, MA: Harvard University, Graduate School of Education,1988. (Tese de doutorado)

39. ACOSTA URQUIDI, M. Efectos de la comunicación masiva en el proceso de socializacion política de los niños mexicanos. (Efeitos da comunicação de massa sobre o processo de socialização política das crianças mexicanas). Revista del Centro de Estudios Educativos (CEE), 1971.

40. BRAVO, G.; LEMBERT, E.; PEREZ, M.P. Motivos por los cuales el niño hace uso de la TV. (Motivos pelos quais a criança utiliza a TV). México: Universidad Anáhuac, 1981. (Tese de Licenciatura) ELKES SCHAPIRA, D. Usos y gratificaciones de la televisión por el niño. (Usos e gratificaçõos da televisão pela criança). México: Universidad Anáhuac, 1981. (Tese de Licenciatura) FERNANDEZ COLLADO, C.; BAUTISTA LUCIO, Maria del Carmo. Usos y gratificaciones de la televisión por el niño. (Usos e gratificações da televisão pela criança). México: Universidad Anáhuac, 1976. (Tese de licenciatura)

41. ROTA, J. Mexican children's use of the mass media as a source of need gratification. (O uso da comunicação de massa pela criança mexicana como fonte de compensação). Relatório entregue à UNAM, 1982.

42. FERNANDEZ COLLADO, C. et al. La televisión y el niño. (A televisão e a criança). Cidade do México: Nueva Biblioteca Pedagógica 56, 1986.

43. ROTA, J.; TREMMEL. Television use and cultural Identity. (O uso da televisão e a identidade cultural). Annual Conference of the International Communication Association. (Relatório apresentado na Conferência Anual da Associação Internacional de Comunicação) São Francisco, 1989.

44. MALAGAMBA, A. La televisión y su impacto en la población infantil de Tijuana. (A televisão e seu impacto na população infantil de Tijuana). Tijuana: Centro de Estudos Fronteiriços do Norte do México, 1986. 
socialização das crianças do que seu estrato sócio-econômico. Este e outros estudos similares levaram muitos a questionar a tese de que a televisão é uma força todo-poderosa, que impõe influências estrangeiras às crianças mexicanas. Os resultados cumulativos desses anos de pesquisa sobre a TV e as crianças promoveram uma "desideologização" dos estudos sobre as audiências mexicanas e renovaram o impulso para a pesquisa empírica.

\section{As aplicações das estratégias de mediação e recepção}

A pesquisa mexicana sobre a criança e a televisão tem levado os pesquisadores a concluir que o processo de recepção da televisão é mais significativo no tipo de efeito que a mídia exerce sobre a audiência do que na mera exposição à $T V$.

A compreensão de que o efeito da TV sobre a criança é resultado de uma complexa negociação que envolve fatores contextuais, começou a desenvolver-se com um estudo mais antigo ${ }^{45}$. Nele a relação entre a criança e a televisão era vista como uma interação levada a efeito dentro de um contexto psicossocial e cultural.

Mais recentemente, Corona ${ }^{46}$ estudou as crianças da pré-escola para compreender como elas utilizavam suas experiências com os super-heróis. Para tanto, ela observou co- mo as crianças imitavam o Super Homem, ou a Mulher Maravilha etc., nas suas brincadeiras durante os recreios escolares. Num outro estudo orientado de forma semelhante, Zires ${ }^{47}$ examinou em profundidade a relação entre a assistência à televisão e os comportamentos ritualísticos das crianças.

Na Universidade Ibero-Americana, na Cidade do México, uma linha de pesquisa ligeiramente diversa analisou como a televisão afeta o comportamento infantil em outras situações, longe do aparelho de TV. Os programas a que as crianças assistem na televisão, fornecem-lhes "roteiros" pelos quais elas podem padronizar seus comportamentos perante outras situações de vida, porém condicionados pelos muitos e variados fatores que se impingem e medeiam tais situações. A criança como um "aprendiz cultural" imerso na experiência do aprendizado da vida numa comunidade onde a comunicação de massa é parte, mas apenas parte, das influências culturais ${ }^{48}$.

\section{Perspectivas e desafios}

Três tendências coincidiram com três estágios históricos na evolução da pesquisa mexicana sobre criança e televisão. A primeira perguntava: "Qual o efeito da TV sobre a criança?". A segunda perguntava: "O que as crianças fazem com a TV?". Agora temos um número maior de perguntas sendo feitas: "Como se dá o processo de recepção entre as crianças?", "Quais os processos

45. CEMPAE. La televisión y el niño de 3 a 6 años de edad. (A televisão e a criança de três a seis anos de idade). Cidade do México, 1976.

46. CORONA, S. El genio de la botella. (O gênio da garrafa). Cidade do México: UAM-X, 1986. CORONA, S. Televisión y lueo infantil: un encuentro cercano. (Televisão e lugar infantil. Um encontro íntimo) Cidade do México: UAM-X, 1989.

47.ZIRES, M. El cerimonial televisivo: un espacio de juego y ilusión. (O cerimonial televisivo: um espaço de jogo e ilusão). Cuadernos del TICOM, n.39, Cidade do México: UAM-X, 1986.

48. OROZCO GOMÉZ, G. Mediation practices in TV's reception process. (As práticas de mediaçāo no processo de recepção da televisão). International Association for Mass Communication Research (Relatório à Conferência da Associação Internacional de Pesquisas sobre Comunicação de Massas), São Paulo, 1992. 
sociais que interagem com a TV para influenciar as crianças?", "Como é a percepção infantil da TV mediada por outras forças?" e "Como poderão ser melhor estruturadas as estratégias de recepção em família e nas escolas?".

Aspectos metodológicos são complicados por questões epistemológicas. Cornejo ${ }^{49}$ usou técnicas de psicodrama para recriar e analisar as experiências de recepção infantil da televisão e as estratégias familiares e escolares concernentes à recep- ção, bem como à percepção infantil da intervenção adulta em seus padrões de recepção.

A interação entre a criança e a televisão é extremamente complexa. $O$ processo de recepção da televisão é intermediado por uma enorme gama de fatores. Capturar, compreender, além de prever e explicar esse processo, permanecerá como um desafio maior para os pesquisadores de televisão.
Resumo: Os autores realizam um levantamento sobre as pesquisas que envolvem o tema televisão e criança. Situam as diferentes abordagens teóricas desde a dos "estudos dos efeitos", passando pela dos "usos dos meios de comunicação", até as atuais problemáticas sobre os processos, estratégias e mediaçōes da recepção.

Palavras-chave: televisão, criança, recepção, pesquisa, audiência.

\begin{abstract}
The authors accomplish a gathering of researches concerning the theme television and children. They point out the different theoretical approaches starting with the studies of the effects and uses and then observing the current problems of the procedures, strategies and mediations of reception.
\end{abstract}

Key-words: television, children, reception, research, audience.

49. CORNEJO PORTUGAL, I. Dramatizando la recepción televisiva de los niños. (Dramatizando a recepção televisiva das crianças). Cuadernos de Comunicación y Sociedad, n.13, Guadalajara: CEIC Universidad de Guadalajara. [s.d.] ALMEYDA, L.; VILLAZON, G.; GUTIERREZ, M. Funciones que desempeña la TV para el niño mexicano. (Funçōes que desempenha a TV para a criança mexicana). México: Universidad Anáhuac, 1977. (Tese de Licenciatura) WOBER, J.M. Children's views of leaders, and their experience of the election. (A visão das crianças sobre os líderes e sua experiência em eleições). Londres: ITC Research Departament Reference Paper (Relatório de Referência do Departamento de Pesquisa do ITC), 1992. 